\title{
COST OPTIMIZATION STUDY OF TWO-STEP HELICAL GEARBOXES WITH FIRST STAGE DOUBLE GEAR SETS
}

\author{
Dr. VU NGOC PI ${ }^{1}$, Dr. NGUYEN DINH NGOC ${ }^{2}$, Dr. TRAN THI HONG ${ }^{3} \&$ Dr. NGUYEN HONG LINH ${ }^{4}$ \\ ${ }^{1}$ Associate Professor, Mechanical Engineering Faculty, Thai Nguyen University of Technology, Thai Nguyen City, Vietnam. \\ ${ }^{2}$ Assistant Professor, Mechanical Engineering Faculty, Thai Nguyen University of Technology, Thai Nguyen City, Vietnam. \\ ${ }^{3}$ Associate Professor, Center of Excellence for Automation and Precision Mechanical Engineering, Nguyen Tat Thanh
}

University, Ho Chi Minh City, Vietnam.

${ }^{4}$ Assistant Professor, Mechanical and Automotive Engineering Faculty, Electric Power University, Hanoi City, Vietnam ABSTRACT
One of the important goals of the optimized gearbox design is that the gearbox cost is minimized. However, so far, there
has been no research about the design of a Two-step Helical Gearboxe (THG) with First Stage Double Gearsets (FSDG)
and optimum gear ratios to achieve the lowest cost. This paper presents the results of research on the influence of input
parameters on the optimum partial gear ratios of the mentioned gearbox. To do that, a simulation experiment was
designed and performed. Moreover, a regression formula for finding the optimum gear ratio was proposed. Evaluation
results show that the formula is very suitable for the experimental data.

KEYWORDS: Helical Gearbox, Cost Optimization, Gear Ratio \& Optimum Gearbox Design

Received: Mar 14, 2020; Accepted: Apr 04, 2020; Published: May 19, 2020; Paper Id.: IJMPERDJUN202053

\section{INTRODUCTION}

Up to now, the optimal gearbox design has received much attention from researchers. Various studies were conducted in several different directions, such as determining the optimal parameters to reduce gearbox vibration $[1,2]$, to achieve the smallest gear mass [3-8], the smallest gearbox length [3, 8-13], or the smallest gearbox crosssection [3, 8, 14-20]. Besides, the optimal design of gearboxes has carried out with the mechanical system containing a V-belt [21-26] or a chain drive [27-30]. Studies have also been done with various types of gearboxes such as helical gearboxes [6, 11, 12, 15, 17, 27, 28, 31-33], bevel gearboxes [14, 22, 23, 32, 34-36] or worm gearboxes [30, 37-40]. Recently, a cost optimization study for a three-stage helical gearbox has been introduced [41]. However, so far there has been no research on optimization design for minimum cost of two-step helical gearboxes with first stage double gearsets.

This article presents the results of optimum design of a THG with FSDG. In particular, the influence of main design parameters on the optimum gear ratios has been analyzed by designing and performing a simulation experiment. In addition, the optimum gear ratios can easily be found by proposed regression models.

\section{METHODOLOGY}

Itis the fact that the costs of bearings, gears, shafts, casing is found to have strong influence on the cost of a given gearbox. In this study, the cost of bearings will be ignored because of complex cost determination. Consequently, the cost of a THG with FSDG, $C$, can be determined by the following equations: 


$$
C=C_{g}+C_{g h}+C_{s}
$$

In which, $C_{g}, C_{g h}$, and $C_{s}$ are the cost of gears, gearbox housing and shafts, respectively. It should be noticed that the cost of a gear contains the cost of used materials, machining process, heat treatment, operators, etc. These costs construct the final price of a gear. In terms of commerce, the price of a gear can be usually determined by unit price per kilogram which regularly changes according to markets. In the current study, these cost elements are considered as variables and calculated by the following equations:

$$
\begin{aligned}
& C_{g}=c_{g, m} \cdot m_{g} \\
& C_{g h}=c_{g h, m} \cdot m_{g h} \\
& C_{s}=c_{s, m} \cdot m_{s}
\end{aligned}
$$

Where, $c_{g, m}, c_{g h, m}$, and $c_{s, m}$ are the cost of gears, gearbox housing, and shafts (USD/kg); $m_{g}, m_{g h}$, and $m_{s}$ are the mass of gears, gearbox housing, and shafts $(\mathrm{kg})$. In this work, $c_{g, m}, c_{g h, m}$, and $c_{s, m}$ are variables and $m_{g}, m_{g h}$, and $m_{s}$ are defined as below:

$$
\begin{aligned}
& m_{g}=\rho_{1} \cdot\left[2 \cdot\left(\frac{\pi \cdot e_{1} \cdot d_{w 11}^{2} \cdot b_{w 1}}{4}+\frac{\pi \cdot e_{2} \cdot d_{w 21}^{2} \cdot b_{w 1}}{4}\right)+\left(\frac{\pi \cdot e_{1} \cdot d_{w 12}^{2} \cdot b_{w 2}}{4}+\frac{\pi \cdot e_{2} \cdot d_{w 22}^{2} \cdot b_{w 2}}{4}\right)\right] \\
& m_{g h}=\rho_{2} \cdot\left[2 \cdot L \cdot B_{1} \cdot 1.5 \cdot S_{G}+2 \cdot L \cdot H \cdot S_{G}+2 \cdot B_{2} \cdot H \cdot S_{G}\right] \\
& m_{s}=\rho_{3} \cdot \frac{\pi}{4} \cdot\left(d_{1}^{2} \cdot l_{1}+d_{2}^{2} \cdot l_{2}+d_{3}^{2} \cdot l_{3}\right)
\end{aligned}
$$

Wherein, $\rho_{1}, \rho_{2}$, and $\rho_{3}$ are the weight density of materials of gear, gearbox housing, and shafts, respectively; $\rho_{1}=\rho_{3}=7.82 ; \rho_{2}=7.2[42] ; e_{1}=1$ and $e_{2}=0.6 ; L, S_{G}, H, B_{1}$, and $B_{2}$ are the element dimensions of gearbox housing (Figure 1) which can be found by:

$$
\begin{aligned}
& L=\left(d_{w 11}+d_{w 21} / 2+d_{w 12} / 2+d_{w 22}+22.5\right) / 0.975[4] \\
& S_{G}=0.005 \cdot L+4.5[4] \\
& H=\max \left(d_{w 21}, d_{w 22}\right)+6.5 \cdot S_{G} \\
& B_{1}=2 \cdot b_{w 1}+b_{w 2}+5 \cdot S_{G} \\
& B_{2}=B_{1}-2 \cdot S_{G}
\end{aligned}
$$

In addition, $b_{w 1}, b_{w 2}$ are the gear widths; $d_{w 11}, d_{w 21}, d_{w 12}$, and $d_{w 22}$ are the pitch diameters of the pinion and the gear of the first and second stages. These parameters can be calculated by below equations [43]:

$$
\begin{aligned}
& b_{w 1}=X_{b a 1} \cdot a_{w 1} \\
& b_{w 2}=X_{b a 2} \cdot a_{w 2} \\
& d_{w 11}=2 \cdot a_{w 1} /\left(u_{1}+1\right) \\
& d_{w 21}=2 \cdot a_{w 1} \cdot u_{1} /\left(u_{1}+1\right)
\end{aligned}
$$




$$
\begin{aligned}
& d_{w 12}=2 \cdot a_{w 2} /\left(u_{2}+1\right) \\
& d_{w 22}=2 \cdot a_{w 2} \cdot u_{2} /\left(u_{2}+1\right) \\
& a_{w 1}=43 \cdot\left(u_{1}+1\right) \cdot \sqrt[3]{T_{11} \cdot k_{H \beta} /\left(\left[\sigma_{H 1}\right]^{2} \cdot u_{1} \cdot X_{b a 1}\right)}[43] \\
& a_{w 2}=43 \cdot\left(u_{2}+1\right) \cdot \sqrt[3]{T_{12} \cdot k_{H \beta} /\left(\left[\sigma_{H 2}\right]^{2} \cdot u_{2} \cdot X_{b a 2}\right)}[43] \\
& d_{1}=\sqrt[3]{T_{11} /(0.2 \cdot[\tau])}[43] \\
& d_{2}=\sqrt[3]{T_{12} /(0.2 \cdot[\tau])}[43] \\
& d_{3}=\sqrt[3]{T_{13} /(0.2 \cdot[\tau])}[43] \\
& \left.l_{1}=B_{1}+1.2 \cdot d_{1} \text { (Figure } 1\right) \\
& l_{2}=B_{1}(\text { Figure } 1) \\
& \left.l_{3}=B_{1}+1.2 \cdot d_{3} \text { (Figure } 1\right)
\end{aligned}
$$
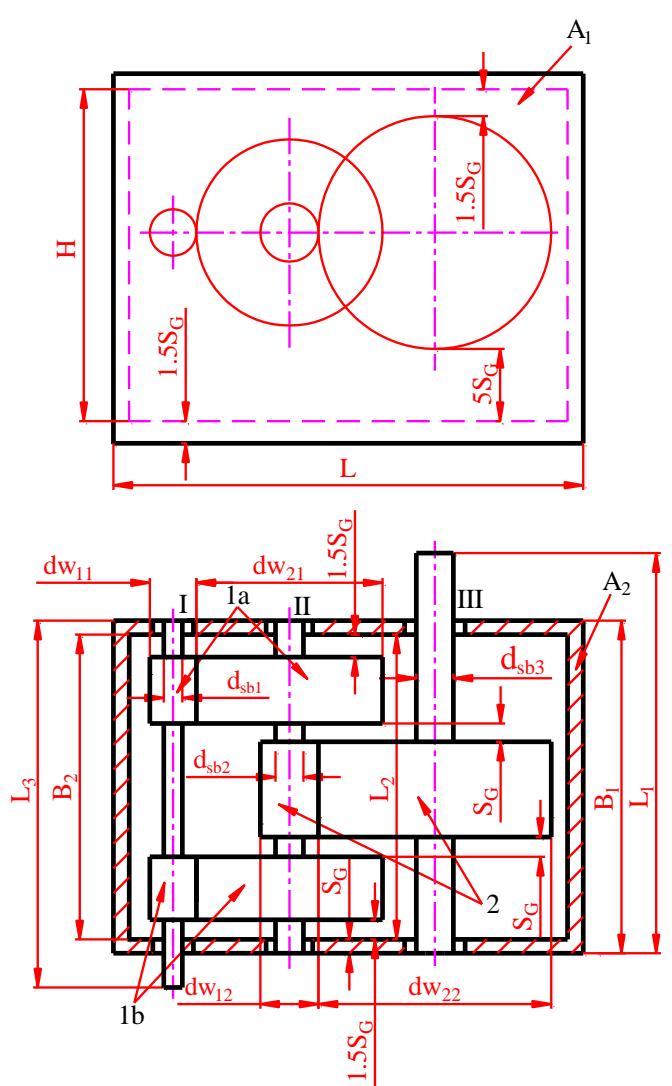

Figure 1: Calculated Schema.

In the equations (19) and (20), $k_{H \beta}$ is the contacting load coefficient which can be chosen by 1.1 [43].

From the above analysis, for minimizing the reducer cost, the objective function of the optimization problem can be designated as follows: 
Minimize $C$

With the following constraints:

$$
\begin{aligned}
& 1 \leq u_{1} \leq 9 \\
& 1 \leq u_{2} \leq 9
\end{aligned}
$$

Nevertheless, it is known that $u_{t}=u_{1} \cdot u_{2}$ is the relation between total gearbox ratio and partial ratios. Hence, the optimization of $u_{1}$ is sufficient, while the optimum ratio of $u_{2}$ can be obtained by the expression: $u_{2}=u_{t} / u_{1}$.

\section{EXPERMENTAL WORK}

Table 1: Main Design Factors

\begin{tabular}{|l|c|c|c|c|}
\hline \multicolumn{1}{|c|}{ Parameter } & Code & Unit & Low & High \\
\hline Total gear ratio & $u_{t}$ & - & 10 & 50 \\
\hline Gear face ratio of first step & $X_{b a 1}$ & - & 0.3 & 0.35 \\
\hline Wheel face ratio of second step & $X_{b a 2}$ & - & 0.35 & 0.4 \\
\hline Allowable contact stress of first step & $A S_{1}$ & $\mathrm{MPa}$ & 350 & 420 \\
\hline Allowable contact stress of second step & $A S_{2}$ & $\mathrm{MPa}$ & 350 & 420 \\
\hline Output torque & $T_{\text {out }}$ & $\mathrm{Nmm}$ & 100 & 10000 \\
\hline Gearbox housing cost & $C_{g h}$ & $\mathrm{USD} / \mathrm{kg}$ & 1 & 5 \\
\hline Gear cost & $C_{g}$ & $\mathrm{USD} / \mathrm{kg}$ & 2 & 9 \\
\hline Shaft cost & $C_{s}$ & $\mathrm{USD} / \mathrm{kg}$ & 1.5 & 5 \\
\hline
\end{tabular}

Table 2: Runs of Experiment and Values of Response

\begin{tabular}{|c|c|c|c|c|c|c|c|c|c|c|c|c|c|}
\hline Std Order & Run Order & Center Pt & Blocks & $u_{t}$ & $X_{b a 1}$ & $X_{b a 2}$ & $A S_{1}$ & $A S_{2}$ & $T_{\text {out }}$ & $C_{g h}$ & $C_{g}$ & $C_{S}$ & $u_{1}$ \\
\hline 117 & 1 & 1 & 1 & 5 & 0.3 & 0.4 & 350 & 420 & 10000 & 5 & 9 & 1.5 & 1.56 \\
\hline 50 & 2 & 1 & 1 & 45 & 0.3 & 0.35 & 350 & 420 & 10000 & 1 & 2 & 1.5 & 6.66 \\
\hline 51 & 3 & 1 & 1 & 5 & 0.35 & 0.35 & 350 & 420 & 10000 & 1 & 9 & 5 & 1.24 \\
\hline 101 & 4 & 1 & 1 & 5 & 0.3 & 0.4 & 350 & 350 & 10000 & 5 & 9 & 5 & 1.42 \\
\hline 31 & 5 & 1 & 1 & 5 & 0.35 & 0.4 & 420 & 420 & 100 & 1 & 2 & 5 & 1.00 \\
\hline 11 & 6 & 1 & 1 & 5 & 0.35 & 0.35 & 420 & 350 & 100 & 1 & 9 & 5 & 1.40 \\
\hline$\ldots$ & & & & & & & & & & & & & \\
\hline 74 & 127 & 1 & 1 & 45 & 0.3 & 0.35 & 420 & 350 & 100 & 5 & 9 & 5 & 8.99 \\
\hline 120 & 128 & 1 & 1 & 45 & 0.35 & 0.4 & 350 & 420 & 10000 & 5 & 2 & 5 & 5.10 \\
\hline
\end{tabular}

To perform the optimization problem which is defined by Equations (27) and (28), a simulation experiment was designed and conducted. For the experiment, a 2-level factorial experiment with 1/4 fraction was selected by Minitab@19 and a number of $2^{9-2}=128$ tests were carried out. In this case, the Taguchi method which reduces the number of test is not used. The screening experiment used herein is not only a simple way to investigate the influence of nine factors (Table 1) on the response, but also propose the mathematical models instead of the Taguchi method. Table 2 shows various input parameters and the response (the optimum gear ratio $u_{1}$ ).

\section{RESULTS AND DISCUSSIONS}

\subsection{Effect of Main Design Factors}

Figure 2 describes the effect of main design factors on the optimum gear ratio of the first step $u_{1}$. From this graph, it is clear that $u_{1}$ is greatly influenced by $u_{t}$. It increases sharply when $u_{t}$ increases. Besides, $u_{1}$ has a positive relationship 
with $A S_{1}, C_{g}, C_{g h}$ while it has an inverse relation with $X_{b a 1}, X_{b a 2}, A S_{2}, T_{\text {out }}$ and $C_{s}$.

Main Effects Plot for u1 Fitted Means

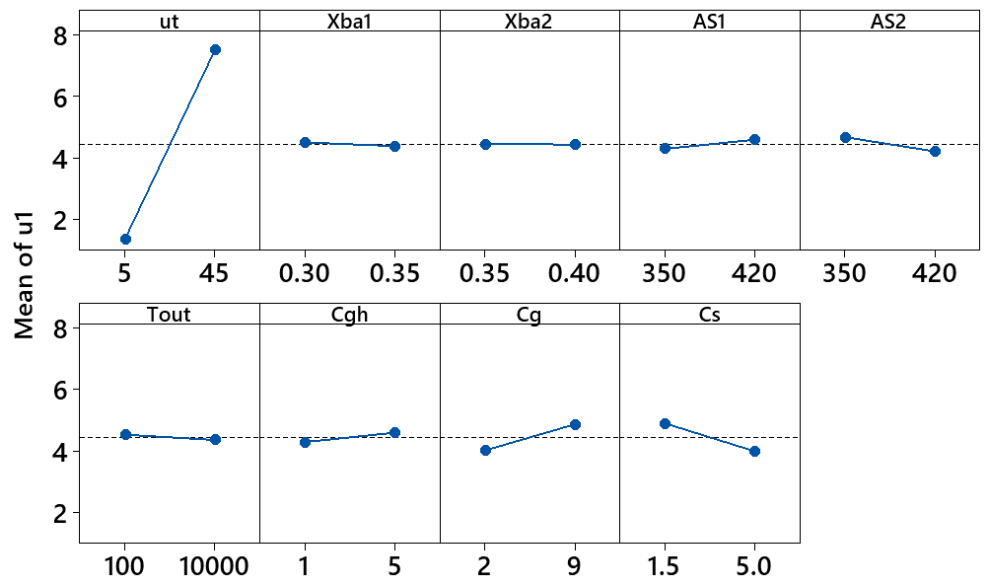

Figure 2: Influences of Input Factors on $u_{1}$.

\section{Interaction Plot for u1 Fitted Means}

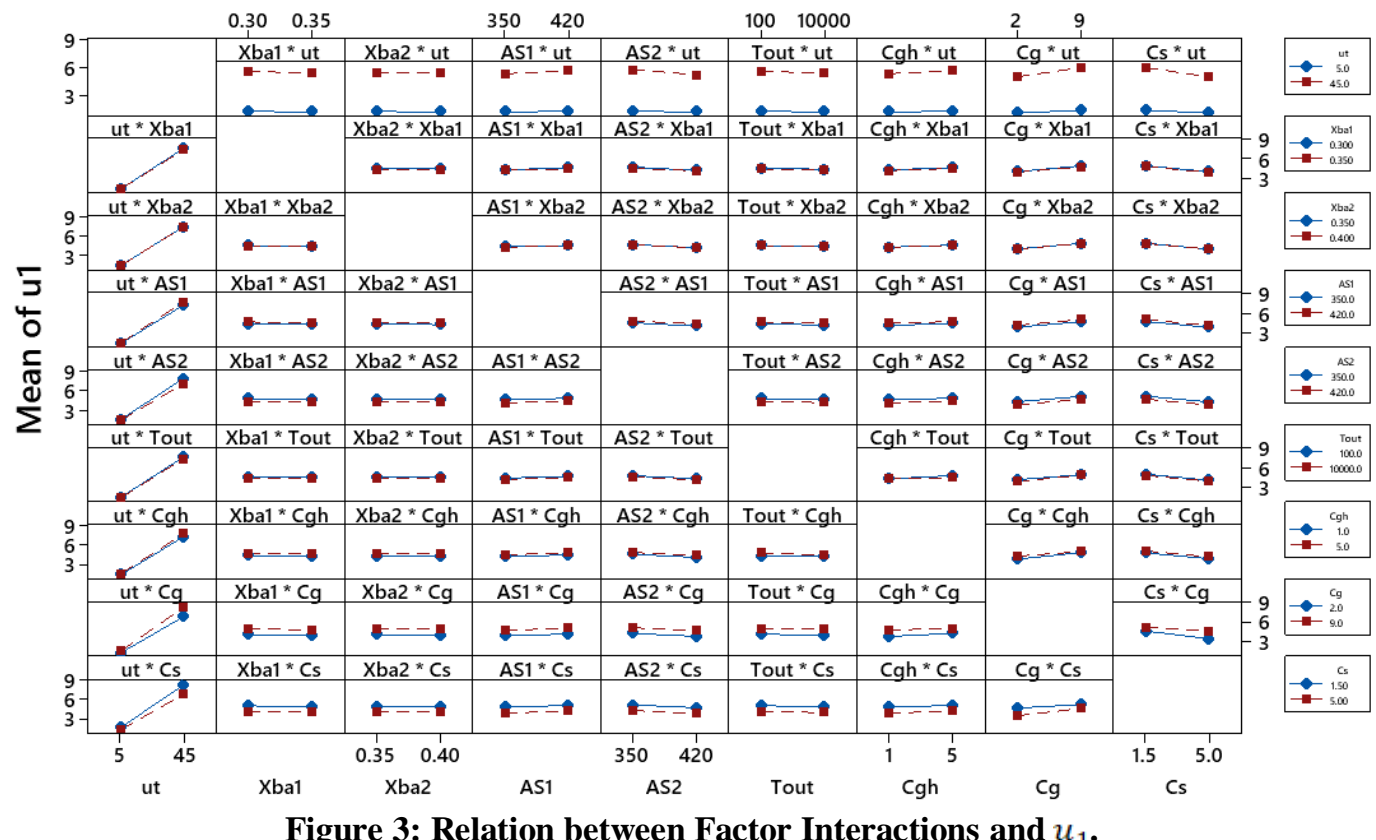

The relationship between the interactions of main design factors and $u_{1}$ can be understood by Figure 3 . Indeed, it can be seen that in term of interactions, $C_{g}$ and $C_{s}$ have strong influences on the response in both low and high values, such as HA $\left(\mathrm{u}_{\mathrm{t}} * C_{g}\right), \mathrm{HB}\left(\mathrm{Xba}_{1} * C_{g}\right), \mathrm{HC}\left(\mathrm{Xba}_{2} * C_{g}\right), \mathrm{HD}\left(\mathrm{AS} 1 * C_{g}\right), \mathrm{HE}\left(\mathrm{AS} 2 * C_{g}\right), \mathrm{HF}\left(\mathrm{T}_{\text {out }} * C_{g}\right), \mathrm{HG}\left(C_{g h} * C_{g}\right), \mathrm{JA}$ $\left(\mathrm{u}_{\mathrm{t}} * C_{s}\right), \mathrm{JB}\left(\mathrm{Xba}_{1} * C_{s}\right), \mathrm{JC}\left(\mathrm{Xba}_{2} * C_{s}\right), \mathrm{JD}\left(\mathrm{AS} 1 * C_{s}\right), \mathrm{JE}\left(\mathrm{AS} 2 * C_{s}\right), \mathrm{JF}\left(\mathrm{T}_{\text {out }} * C_{s}\right), \mathrm{JG}\left(C_{g h} * C_{s}\right), \mathrm{JH}\left(C_{g} * C_{s}\right)$. However, $u_{t}$ has the strongest impact on $u_{1}$, but having the minor effect on the it when $u_{t}$ interact with other input parameters. These 
are dominant when $u_{t}$ varies from 5 to 45 like $\mathrm{AB}, \mathrm{AC}, \mathrm{AD}, \mathrm{AE}, \mathrm{AF}$, and $\mathrm{AG}$.

The Normal plot of Standardized Effects was presented in Figure 4. This graph not only describes the relationship of the main design parameters to $u_{1}$, but it also indicates whether the relationship is positive or inverse. From the Plot, factors $u_{1}, C_{g}, C_{g h}, A S_{1}$ and interactions $\mathrm{AH}, \mathrm{HJ}, \mathrm{AD}, \mathrm{AG}$, and $\mathrm{FH}$ have a positive effect. Besides, factors $C_{s}, A S_{2}, \mathrm{~F}$ and $\mathrm{AJ}, \mathrm{AE}, \mathrm{FG}$, and $\mathrm{AF}$ are inverse on $u_{1}$.

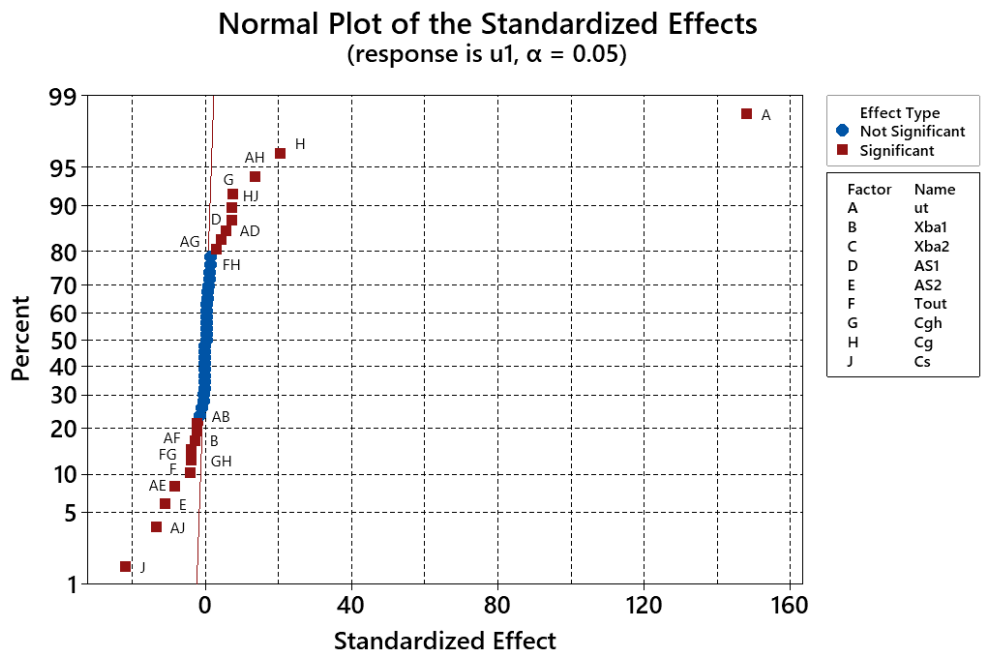

Figure 4: Normal Plot of the Standardized Effects.

\subsection{Proposed Equation for Calculating $u_{1}$}

To find a model to determine $u_{1}$, Minitab @ 19 was used for a regression process with two interactive elements and the significance of $\alpha=0.05$. After neglecting unimportant influence factors, the predictable coefficients for $u_{1}$ are presented in Table 3. It was noted that the P-values of main design factors and interactions are less than $\alpha=0.05$. That means these factors are robust influence on $u_{1}$. As a result, the proposed model for calculating $u_{1}$ is given as follow:

$$
\begin{aligned}
u_{1}=0.96+0.218 & \cdot u_{t}+0.07 \cdot X_{\text {ba } 1}+0.000119 \cdot A S_{1}-0.000444 \cdot A S_{2}+10^{-7} \cdot T_{\text {out }}+0.128 \cdot C_{g h} \\
& -0.0401 \cdot C_{g}-0.191 \cdot C_{s}-0.0973 \cdot u_{t} \cdot X_{b a 1}+0.000163 \cdot u_{t} \cdot A S_{1}-0.000248 \cdot u_{t} \cdot A S_{2} \\
& -10^{-7} \cdot u_{t} \cdot T_{\text {out }}+0.002205 \cdot u_{t} \cdot C_{g h}+0.004012 \cdot u_{t} \cdot C_{g}-0.008056 \cdot u_{t} \cdot C_{s} \\
& -0.000008 \cdot T_{\text {out }} \cdot C_{g h}+0.000004 \cdot T_{\text {out }} \cdot C_{g}-0.01189 \cdot C_{g h} \cdot C_{g}+0.0243 \cdot C_{g} \cdot C_{s}
\end{aligned}
$$

It is found that the test data is very suitable with the proposed equation as all of the values of R-square are more than $98 \%$ (Table 3). Therefore, this regression equation is great to use to determine $u_{1}$. After having $u_{1}$, the optimal gear ratio $u_{2}$ can easily be found by $u_{2}=u_{t} / u_{1}$. 
Table 3: Coded Coefficients for Proposed Model Coded Coefficients

\begin{tabular}{|c|c|c|c|c|c|c|}
\hline Term & Effect & Coef & SE Coef & T-Value & P-Value & V \\
\hline Constant & & 4.4532 & 0.0193 & 231.04 & 0.000 & \\
\hline ut & 6.1430 & 3.0715 & 0.0193 & 159.35 & 0.000 & \\
\hline ba1 & -0.1183 & -0.0591 & 0.0193 & -3.07 & 0.003 & \\
\hline AS1 & 0.2933 & 0.1466 & 0.0193 & 7.61 & .000 & \\
\hline AS2 & 0.4648 & -0.2324 & 0.0193 & -12.06 & .000 & \\
\hline Tout & .1702 & -0.0851 & 0.0193 & -4.41 & .000 & \\
\hline Cgh & 0.3042 & 0.1521 & 0.0193 & 7.89 & 0.000 & \\
\hline $\mathrm{Cg}$ & 08 & 0.4254 & 93 & 2.07 & .000 & . \\
\hline Cs & -0.9055 & -0.4527 & 0.0193 & -23.49 & 0.000 & \\
\hline$u^{*}{ }^{*}$ & & -0.0487 & & -2.53 & 013 & 1. \\
\hline ut*AS1 & 0.2280 & 0.1140 & 0.0193 & 5.91 & 0.000 & 1. \\
\hline ut*AS2 & -0.3470 & -0.1735 & 0.0193 & -9.00 & 0.000 & 1 \\
\hline ut*Tout & -0.0980 & -0.0490 & 0.0193 & -2.54 & 0.012 & 1. \\
\hline$u^{*}{ }^{*} \mathrm{Cgh}$ & 0.1764 & 0.0882 & 0.0 & 4.58 & 0.000 & 1. \\
\hline $\mathrm{ut}^{*} \mathrm{Cg}$ & 0.5617 & 0.2809 & 0.0193 & 14.57 & .000 & 1. \\
\hline $\mathrm{ut}^{*} \mathrm{Cs}$ & -0.5639 & -0.2820 & 0.0193 & -14.63 & 0.000 & 1. \\
\hline Tout ${ }^{\star} \mathrm{Cgh}$ & -0.1636 & -0.0818 & 0.0193 & -4.24 & 0.000 & 1 \\
\hline Tout ${ }^{\star} \mathrm{Cg}$ & 0.1236 & 0.0618 & 0.0193 & 3.21 & 0.002 & 1. \\
\hline $\mathrm{Cgh}^{\star} \mathrm{Cg}$ & -0.1664 & -0.0832 & 0.0193 & -4.32 & 0.000 & 1 \\
\hline $\mathrm{Cg}^{\star} \mathrm{Cs}$ & 0.2977 & 0.1488 & 0.0193 & 7.72 & 0.000 & 1. \\
\hline
\end{tabular}

Model Summary

\begin{tabular}{rrrr} 
S & R-sq & R-sq(adj) & R-sq(pred) \\
\hline 0.218068 & $99.61 \%$ & $99.54 \%$ & $99.45 \%$
\end{tabular}

Table 4: ANOVA for $u_{1}$

\begin{tabular}{|c|c|c|c|c|c|}
\hline Source & DF & Adj SS & Adj MS & F-Value & P.Value \\
\hline Model & 19 & 1303.42 & 68.60 & 1442.60 & 0.000 \\
\hline Linear & 8 & 1270.96 & 158.87 & 3340.85 & 0.000 \\
\hline ut & 1 & 1207.55 & 1207.55 & 25393.56 & 0.000 \\
\hline Xba1 & 1 & 0.45 & 0.45 & 9.41 & 0.003 \\
\hline AS1 & 1 & 2.75 & 2.75 & 57.88 & 0.000 \\
\hline AS2 & 1 & 6.91 & 6.91 & 145.41 & 0.000 \\
\hline Tout & 1 & 0.93 & 0.93 & 19.48 & 0.000 \\
\hline Cgh & 1 & 2.96 & 2.96 & 62.28 & 0.000 \\
\hline $\mathrm{Cq}$ & 1 & 23.16 & 23.16 & 487.08 & 0.000 \\
\hline Cs & 1 & 26.24 & 26.24 & 551.71 & 0.000 \\
\hline 2-Way Interactions & 11 & 32.46 & 2.95 & 62.06 & 0.000 \\
\hline ut*Xba1 & 1 & 0.30 & 0.30 & 6.38 & 0.013 \\
\hline ut*AS1 & 1 & 1.66 & 1.66 & 34.97 & 0.000 \\
\hline ut*AS2 & 1 & 3.85 & 3.85 & 81.04 & 0.000 \\
\hline ut*Tout & 1 & 0.31 & 0.31 & 6.46 & 0.012 \\
\hline ut*Cah & 1 & 1.00 & 1.00 & 20.94 & 0.000 \\
\hline $\mathrm{ut}^{*} \mathrm{Cg}$ & 1 & 10.10 & 10.10 & 212.33 & 0.000 \\
\hline$u t^{*} \mathrm{Cs}$ & 1 & 10.18 & 10.18 & 213.98 & 0.000 \\
\hline Tout ${ }^{\star} \mathrm{Cgh}$ & 1 & 0.86 & 0.86 & 18.01 & 0.000 \\
\hline Tout ${ }^{\star} \mathrm{Cq}$ & 1 & 0.49 & 0.49 & 10.28 & 0.002 \\
\hline $\mathrm{Cgh}^{\star} \mathrm{Cg}$ & 1 & 0.89 & 0.89 & 18.63 & 0.000 \\
\hline $\mathrm{Cg}{ }^{*} \mathrm{Cs}$ & 1 & 2.84 & 2.84 & 59.62 & 0.000 \\
\hline Error & 108 & 5.14 & 0.05 & & \\
\hline Total & 127 & 1308.55 & & & \\
\hline
\end{tabular}

\footnotetext{
S R-sq R-sq(adj) R-sq(pred)

$\begin{array}{llll}0.218068 & 99.61 \% & 99.54 \% & 99.45 \%\end{array}$
} 


\subsection{Analysis of Variance}

The Analysis Of Variance (ANOVA) is carried out and the results are revealed in Table 4 where the weak influences are eliminated. From the table, it is visualized that the parameters of A, D, E, G, H, J, AE, AH, AJ, and HJ exhibit the F-value superior to 50. These have the static importance as all of the values of R-square are higher than $99 \%$.

\subsection{Validating Regression Equation}

The error valuation between the experimental data and the regression equation of $u_{1}$ is designated in Figure 5 . It can be seen from Figure 5a that the error contribution is very similar to the normal distribution. Figure 5b shows the relation between the residual and model fitted values. It is found that they are arbitrary data. That means the observation order depends on the control parameters. Furthermore, the random connection between the residual and the observation data is also random.

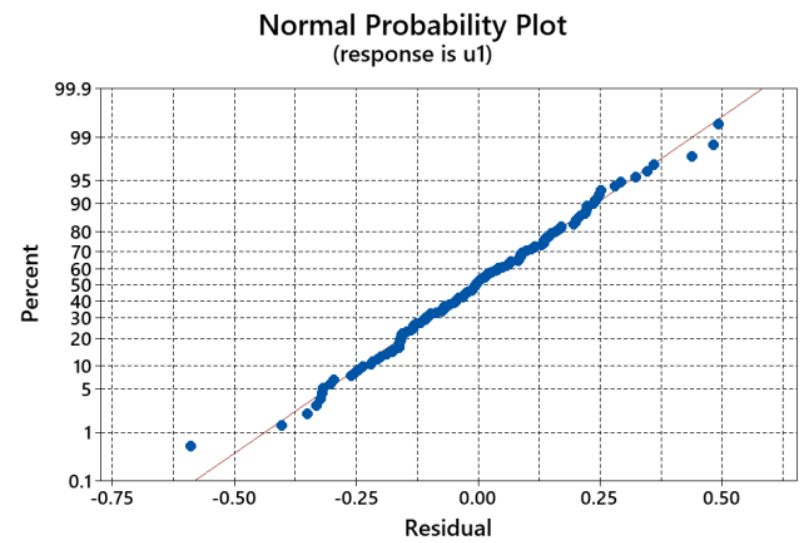

(a)

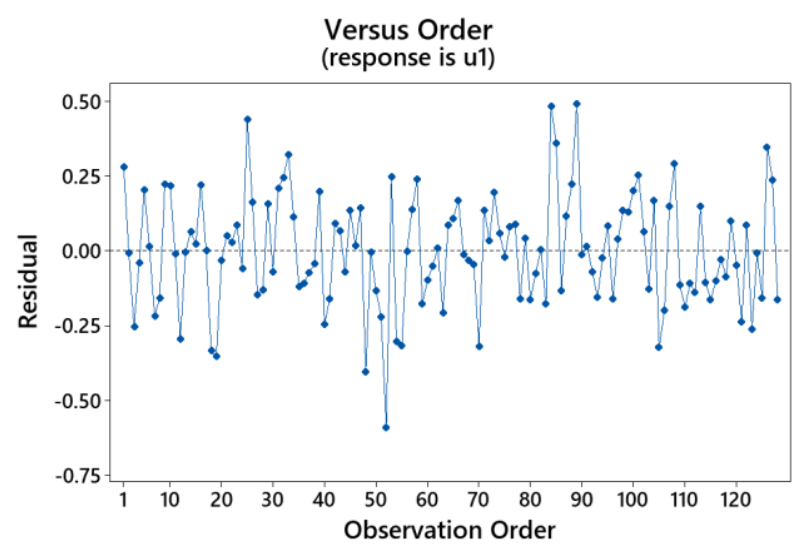

(b)

Figure 5: Estimating Errors between Experiments and Regression Equation of $u_{1}$.

\section{CONCLUSIONS}

The present work deals with cost optimization design of THG with FSDG. In this work, the effects of key design factors on the optimal gear ratios were evaluated by designing and performing a simulation experiment. In addition, optimal gear ratios can easily be found using the suggested regression equations. Also, several conclusions are given as follows:

- The effect of $u_{t}$ on the optimal gear ratio of the first step $u_{1}$ is much more than that of other main design factors.

- The F-value of main design factors and their interactions of A, D, E, G, H, J, AE, AH, AJ, and HJ are significant for $u_{1}$.

- The suggested regression equation for calculating $u_{1}$ is extremely fit with the data of the experiment (all of the values of R-square are higher than $99 \%$ ).

\section{ACKNOWLEDGEMENTS}

The authors thankfully acknowledge Thai Nguyen University of Technology for supporting this work.

\section{REFERENCES}

1. Inoue, K., D. P. Townsend, and J. J. Coy, Optimum design of a gearbox for low vibration. 1993.

2. Inoue, K., M. Yamanaka, and M. Kihara, Optimum stiffener layout for the reduction of vibration and noise of gearbox housing. 
J. Mech. Des., 2002. 124(3): p. 518-523.

3. Pi, V. N., Optimum determination of partial transmission ratios of three-step helical gearboxes. WSEAS Transactions on Applied and Theoretical Mechanics, 2008. 3: p. 43-42.

4. RÖMHILD, I. and H. Linke, Gezielte Auslegung Von Zahnradgetrieben mit minimaler Masse auf der Basis neuer Berechnungsverfahren. Konstruktion, 1992. 44(7-8): p. 229-236.

5. Hung, L., V. Pi, and N. Du. Optimal calculation of partial transmission ratios of four-step helical gearboxes with second and fourth-step double gear-sets for minimal mass of gears. in The International Symposium on Mechanical Engineering, ISME, Ho Chi Minh city, Vietnam. 2009.

6. Pi, V. N., N. D. Binh, and V. Q. Dac, Phan Quang The, Optimal calculation of total transmission ratio of three-step helical gearboxes for minimum mass of gears. Journal of Science and Technology of 6 Engineering Universities, 2006. 55: p. 91-93.

7. Pi, V. N. Optimal determination of partial transmission ratios of three-step helical gearboxes with first and third-step double gear-sets for minimal mass of gear. in American Conference on Applied Mathematics, MATH. 2008.

8. Pi, V. N., A new study on the optimal prediction of partial transmission ratios of three-step helical gearboxes with second-step double gear-sets. WSEAS Trans. Appl. Theor. Mech, 2007. 2(11): p. 156-163.

9. VAN CUONG, N., K. LE HONG, and T. T. HONG, SPLITTING TOTAL GEAR RATIO OF TWO-STAGE HELICAL REDUCER WITH FIRST-STAGE DOUBLE GEARSETS FOR MINIMAL REDUCER LENGTH.

10. Pi, V. N. Optimal calculation of partial transmission ratios for four-step helical gearboxes with first and third-step double gear-sets for minimal gearbox length. in American Conference on Applied Mathematics (MATH 2008), Harvard, Massachusetts, USA. 2008.

11. Pi, V. N. A new study on optimal calculation of partial transmission ratio of three-step helical reducers. in The 3rd IASME/WSEAS international conference on continuum mechanics, Cambridge, UK. 2008.

12. Pi, V. N. A new study on optimal calculation of partial transmission ratios of two-step helical gearboxes. in 2nd WSEAS International Conference on Computer Engineering and Applications, CEA. 2008.

13. Pi, V. N., Optimal calculation of partial transmission ratios of four-step helical gearboxes for getting minimal gearbox length. World Academy of Science, Engineering and Technology, 2008.

14. Pi, V. N. and N. K. Tuan, Determining Optimum Partial Transmission Ratios of Mechanical Driven Systems Using a Chain Drive and a Two-step Bevel Helical Gearbox. International Journal of Mechanical Engineering and Robotics Research, 2019. $8(5)$.

15. Pi, V. N. and N. K. Tuan, Optimum determination of partial transmission ratios of three-step helical gearboxes for getting minimum cross section dimension. Journal of Environmental Science and Engineering A, 2016. 5: p. 570-573.

16. Pi, V. N. A new study on optimal calculation of partial transmission ratios of three-step helical reducers for getting minimal cross section dimension. in The 2nd WSEAS International Conference on Computer Engineering and Applications (CEA'08), Acapulco, Mexico. 2008.

17. Tuan, N. K., et al. Determining optimal gear ratios of a two-stage helical reducer for getting minimal acreage of cross section. in MATEC Web of Conferences. 2018. EDP Sciences.

18. Pi, V. N., A study on optimal determination of partial transmission ratios of helical gearboxes with second-step double gearsets. Proc. of World Academy of Science, 2008. 27: p. 113-6. 
19. Pi, V. N., et al., A New Study on Determination of Optimum Gear Ratios of a Two-Stage Helical Gearbox, in Advances in Material Sciences and Engineering. 2020, Springer. p. 107-115.

20. Pi, V. N., et al. Calculating optimum gear ratios of a two-stage helical reducer with first stage double gear sets. in IOP Conference Series: Materials Science and Engineering. 2019. IOP Publishing.

21. Cam, N. T. H., et al. Determining optimal partial transmission ratios of mechanical driven systems using a V-belt drive and a helical reducer with second-step double gear-sets. in International Conference on Engineering Research and Applications. 2018. Springer.

22. Pi, V. N., N. T. H. Cam, and N. K. Tuan, Optimum calculation of partial transmission ratios of mechanical driven systems using a V-belt and two-step bevel helical gearbox. J. Environ. Sci. Eng. A, 2016. 5: p. 566.

23. Tuan, N. K., et al. Optimum calculation of partial transmission ratios of mechanical driven systems using a V-belt and a threestep bevel helical gearbox. in International Conference on Engineering Research and Applications. 2018. Springer.

24. Pi, V. N., et al., Determining optimum partial transmission ratios of mechanical driven systems using a V-Belt drive and a three-stage helical reducer, in Advances in Material Sciences and Engineering. 2020, Springer. p. 81-88.

25. Tuan, D. A., N. K. Tuan, and V. N. Pi, Optimum determination of partial transmission ratios of mechanical driven systems using a V-belt and a three-step helical gearbox. J. Environ. Sci. Eng. B, 2017. 6: p. 328-331.

26. Pi, V. N., T. T. Hong, and L. X. Hung. Determining optimal partial transmission ratios of mechanical driven systems using a $V$-belt drive and a two-stage helical reducer. in IOP Conference Series: Materials Science and Engineering. 2019. IOP Publishing.

27. Pi, V. N., T. T. P. Thao, and D. A. Tuan, Optimum determination of partial transmission ratios of mechanical driven systems using a chain drive and two-step helical gearbox. J. Environ. Sci. Eng. B, 2017. 6: p. 80.

28. Cam, N. T. H., et al. A study on determination of optimum partial transmission ratios of mechanical driven systems using a chain drive and a three-step helical reducer. in International Conference on Engineering Research and Applications. 2018. Springer.

29. Pi, V. N., N. K. Tuan, and L. X. Hung, A New Study on Calculation of Optimum Partial Transmission Ratios of Mechanical Driven Systems Using a Chain Drive and a Two-Stage Helical Reducer, in Advances in Material Sciences and Engineering. 2020, Springer. p. 97-105.

30. Le Hong Ky, T. T. H., et al. Calculation of Optimum Gear Ratios of Mechanical Driven Systems Using Worm-Helical Gearbox and Chain Drive. in Advances in Engineering Research and Application: Proceedings of the International Conference on Engineering Research and Applications, ICERA 2019. Springer Nature.

31. Ngoc Pi, V. A method for optimal calculation of total transmission ratio of two step helical gearboxes. in Procedings of the National Conference on Engineering Mechanics. 2001.

32. Kudreavtev, V., I. Gierzaves, and E. Glukharev, Design and calculus of gearboxes. 1971, Mashinostroenie Publishing, Sankt Petersburg.

33. Pi, V. N. A study on optimal calculation of partial transmission ratios of three-step bevel helical gearboxes. in International Workshop on Advanced Computing and Applications (ACOMP 2008). 2008.

34. Ngoc Pi, V. A new and effective method for optimal calculation of total transmission ratio of two step bevel-helical gearboxes. in Proceedings of the International Colloquium on Mechannics of Solids, Fluids, Structures \& Interaction. 2000.

35. Pi, V. N., N. D. Binh, and V. Q. Dac. The, PQ: A new and effective method for optimal splitting of total transmission ratio of 
three step bevel-helical gearboxes. in The Sixth Vietnam Conference on Automation, Hanoi. 2005.

36. Pi, V. N., et al. Determination of optimum gear ratios of a three stage bevel helical gearbox. in IOP Conference Series: Materials Science and Engineering. 2019. IOP Publishing.

37. Pi, V. N. and V. Q. Dac, Calculation of total transmission ratio of two step worm reducers for the best reasonable gearbox housing structure. J. Sci. Technol. Thai Nguyen Univ, 2007. 1(41): p. 65-69.

38. Pi, V. N. and V. Q. Dac, Optimal calculation of partial transmission ratios of worm-helical gear reducers for minimal gearbox length. J. Sci. Technol. Tech. Univ, 2007. 61: p. 73-77.

39. Pi, V. N. and V. Q. Dac, Optimal calculation of total transmission ratio of worm-helical gear reducers. J. Sci. Technol. Thai Nguyen Univ, 2005. 4(36): p. 70-73.

40. Pi, V. N., et al., Determining Optimum Gear Ratios of a Worm-Helical Gearbox for Minimum Acreage of the Cross Section, in Advances in Material Sciences and Engineering. 2020, Springer. p. 89-96.

41. Vu, N.-P., et al., The Influence of Main Design Parameters on the Overall Cost of a Gearbox. Applied Sciences, 2020. 10(7): p. 2365.

42. Toolbox, T. E., Density, Specific Weight and Specific Gravity. https://www.engineeringtoolbox.com/density-specific-weightgravity-d_290.html, (accessed 15/11/2019).

43. Trinh Chat, L. V. U., Calculation of mechanical driven systems. 1996, Education Publisher.

44. Salameh Ahmad Sawalha, Talal M. Abu-Mansour, Nesreen Mosa Al-Salem \& Mohammad Luay M. Shaban, "Steering Speed Suspension Device (Triple "S" Device), to Prevent Burnouts -Tafheet Phenomena ", International Journal of Mechanical Engineering (IJME), Vol. 2, Issue 4, pp. 1-8

45. T. Nireekshana \& V. Ramesh Babu, "Design and Fabrication of Linear Induction Motor for Traction Application ", International Journal of Electrical and Electronics Engineering (IJEEE), Vol. 6, Issue 6, pp. 1-18

46. Gurudutt Sahni, Balpreet Singh \& Ankush Kohli, " Design of Planetary Gear to Use It for Lapping of Wedge of Gate Vlave and Its Benefits over Other Gear Mechanism ", IMPACT: International Journal of Research in Engineering \& Technology (IMPACT: IJRET), Vol. 3, Issue 8, pp.1-6

47. Jamal Nawaser \& Mohammad Amin Rashidifar, "Evaluation of Harmful vibrations caused By sea Waves on Patients with Critical Conditions for Transport by marine Vessels ", BEST: International Journal of Management, Information Technology and Engineering (BEST: IJMITE), Vol. 4, Issue 1, pp. 31-48 

